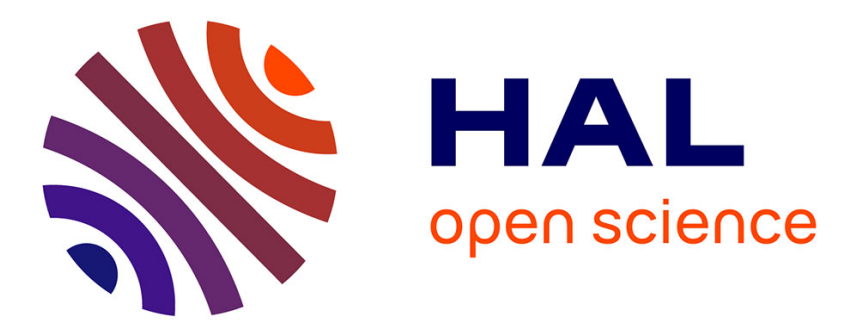

\title{
Longitudinal study on acceptance of food textures between 6 and 18 months
}

\author{
Lauriane Demonteil, Carole Tournier, Agnès Marduel, Marion Dusoulier, \\ Hugo Weenen, Sophie Nicklaus
}

\section{To cite this version:}

Lauriane Demonteil, Carole Tournier, Agnès Marduel, Marion Dusoulier, Hugo Weenen, et al.. Longitudinal study on acceptance of food textures between 6 and 18 months. Food Quality and Preference, 2019, 71 (January 2019), pp.54-65. 10.1016/j.foodqual.2018.05.010 . hal-02620217

\section{HAL Id: hal-02620217 https://hal.inrae.fr/hal-02620217}

Submitted on 25 May 2020

HAL is a multi-disciplinary open access archive for the deposit and dissemination of scientific research documents, whether they are published or not. The documents may come from teaching and research institutions in France or abroad, or from public or private research centers.
L'archive ouverte pluridisciplinaire HAL, est destinée au dépôt et à la diffusion de documents scientifiques de niveau recherche, publiés ou non, émanant des établissements d'enseignement et de recherche français ou étrangers, des laboratoires publics ou privés.

\section{(ㅇ)(1) $\$$}

Distributed under a Creative Commons Attribution - NonCommercial - NoDerivatives| 4.0 


\section{Accepted Manuscript}

Longitudinal study on acceptance of food textures between 6 and 18 months

Lauriane Demonteil, Carole Tournier, Agnès Marduel, Marion Dusoulier, Hugo Weenen, Sophie Nicklaus

PII:

S0950-3293(18)30405-1

DOI: https://doi.org/10.1016/j.foodqual.2018.05.010

Reference: FQAP 3517

To appear in: Food Quality and Preference

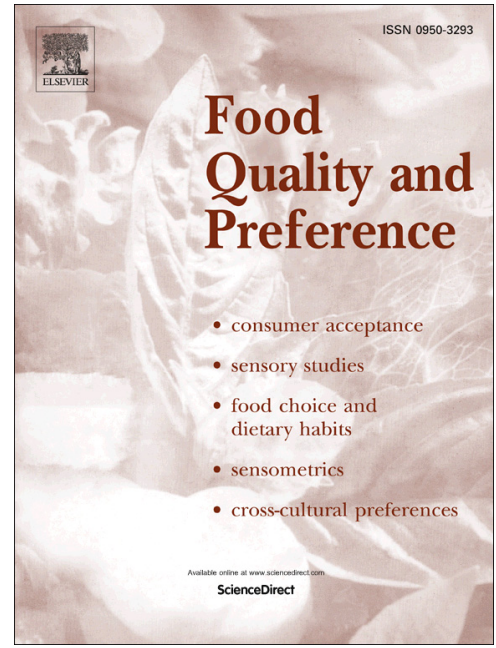

Received Date: $\quad 21$ November 2017

Revised Date: $\quad 10$ April 2018

Accepted Date: $\quad 24$ May 2018

Please cite this article as: Demonteil, L., Tournier, C., Marduel, A., Dusoulier, M., Weenen, H., Nicklaus, S., Longitudinal study on acceptance of food textures between 6 and 18 months, Food Quality and Preference (2018), doi: https://doi.org/10.1016/j.foodqual.2018.05.010

This is a PDF file of an unedited manuscript that has been accepted for publication. As a service to our customers we are providing this early version of the manuscript. The manuscript will undergo copyediting, typesetting, and review of the resulting proof before it is published in its final form. Please note that during the production process errors may be discovered which could affect the content, and all legal disclaimers that apply to the journal pertain. 


\section{Longitudinal study on acceptance of food textures between 6 and 18 months}

\section{Authors:}

Lauriane Demonteil $^{\mathrm{a}}$, Carole Tournier $^{\mathrm{a}}$, Agnès Marduel ${ }^{\mathrm{b}}$, Marion Dusoulier $^{\mathrm{b}}$, Hugo Weenen $^{\mathrm{c}}$, Sophie Nicklaus ${ }^{\mathrm{a}}$

\section{Affiliations:}

${ }^{a}$ Centre des Sciences du Goût et de l'Alimentation, AgroSup Dijon, CNRS, INRA, Université Bourgogne Franche-Comté, Dijon, France.

${ }^{\mathrm{b}}$ Blédina SA, Limonest, France.

${ }^{\mathrm{c}}$ Nutricia Research, Utrecht, The Netherlands.

Author's last names: Demonteil, Tournier, Marduel, Dusoulier, Weenen, Nicklaus

Corresponding author: Sophie NICKLAUS, UMR CSGA INRA, 17 rue Sully, F-21000 Dijon France

Tel: +33380693518; Fax: +33380693227; E-mail: sophie.nicklaus@inra.fr 


\begin{abstract}
The timely complementary food introduction is important for the development of healthy eating. However, little evidence is available about when to introduce which texture during this period. This study aims to fill this gap by measuring the evolution of food texture acceptance and feeding behaviours between 6 and 18 months. Two groups of healthy children participated in the study: at 6,8 , and 10 months $(n=24)$ and at 12,15 and 18 months $(n=25)$, respectively. They were offered foods with different textures (purees, double textures, cooked pieces, sticky and hard foods) at an age when few infants were already familiar with these textures. For each food texture, children's acceptance (ability to process and swallow a food) and feeding behaviours (sucking and chewing) were assessed by the investigator; liking was assessed by parents. At 6 months, pureed and double textures were highly accepted (Acceptance Probability AP $>0.8$ ); when offered at 8 months, cooked pieces were highly accepted $(\mathrm{AP}>0.8)$. Up to 10 months, the acceptance of more complex textures (e.g. cheese, bread crust) increased strongly with age as did chewing behaviour. At 12 months, most food textures were accepted $(\mathrm{AP}>0.5)$, except raw vegetable pieces and pasta $(\mathrm{AP}<0.35)$, and chewing behaviour was predominant over sucking. Up to 18 months, raw vegetable pieces and pasta acceptance increased with age and was $>0.5$ at 18 months. In conclusion, children accepted most textures at an earlier age than their parents' feeding practices; their feeding behaviours depended on age and food texture and acceptance of hard textures was related to the development of chewing.
\end{abstract}

Keywords: food texture; acceptance; children; chewing; complementary feeding

\title{
Highlights
}

- Food texture acceptance was studied longitudinally between 6 and18 mo

- Foods were offered before most of the children received them at home

- Sticky textures were accepted from 8mo; hard foods from $12 \mathrm{mo}$; raw pieces from $18 \mathrm{mo}$

- Chewing emerged at $8 \mathrm{mo}$ and was well established at 10 mo

- The acceptance of hard textures coincided with the emergence of chewing behaviour

\begin{abstract}
Abbreviations
$\mathrm{CF}$, complementary feeding; AP, acceptance probability; SP, sucking probability; $\mathrm{CP}$, chewing probability; BFR: Baby Food Recipe; mo, month(s); G1, group 1; G2, group 2
\end{abstract}




\section{Introduction}

The objective of introducing complementary foods is to gradually move an infant from drinking only milk at approximately 4-6 months to consuming a full range of family foods. This nutritional transition, so-called complementary feeding (CF), is becoming increasingly recognized as important in the development of food preferences and the shaping of healthy and sustainable eating behaviours (Harris \& Coulthard, 2016; Harris \& Mason, 2017; Nicklaus, 2016; Schwartz, Vandenberghe-Descamps, Sulmont-Rossé, Tournier, \& Feron, 2017). How complementary foods should be introduced to children (Fewtrell et al., 2017; Harris \& Coulthard, 2016; Lanigan, Bishop, Kimber, \& Morgan, 2001; Nicklaus, 2016) and the importance of the timing of this introduction (H Coulthard, Harris, \& Emmett, 2009; Northstone, Emmett, Nethersole, \& Team, 2001) is well-documented. However, information regarding what types of food textures are accepted by children at a given age during this specific time frame is still missing.

Food texture is a complex sensory property because it involves different dimensions (structure, mechanical properties and surface) detected through different senses, such as vision and touch in particular (Szczesniak, 2002). For the transition to solid foods, children have to acquire specific feeding skills, and these skills require more effort from a child than the oral manipulation of liquids such as milk. The acceptance of food with a given texture, here defined as the infant's ability to swallow the food, is strongly conditioned by the acquisition of feeding skills, which can develop differently in children of the same age (Carruth \& Skinner, 2002; Carruth, Ziegler, Gordon, \& Hendricks, 2004; S. Nicklaus, Demonteil, \& Tournier, 2015). At the beginning of CF, children process semi-solids (i.e., purees) by sucking because they have only experienced drinking liquids (Torola, Lehtihalmes, Yliherva, \& Olsen, 2012). Between 6 and 12 months the most marked changes in feeding behaviours occur; the primary sucking-swallowing behaviour is gradually replaced by the emergence of chewing behaviour and the ability to move solid foods around the mouth for swallowing (Harris \& Coulthard, 2016; S. Nicklaus et al., 2015; Stolovitz \& Gisel, 1991). These skills are likely to depend on food texture but are little documented (Stolovitz \& Gisel, 1991). Texture-related eating strategies have been reported to vary among infants (Gisel, 1991). Some 6-month-old infants let Cheerios ${ }^{\circledR}$ cereals be softened by saliva then swallowed them using sucking motions, whereas other infants attempted to munch on them (munching corresponds to immature chewing). At 10 months, infants adopt a sucking strategy for applesauce but a munching strategy for cereals. From 10 months on, munching is more 
frequent than sucking (Stolovitz \& Gisel, 1991). By 12 months, munching/chewing behaviour is well-established and continues to develop, still gaining in efficiency at 2-3 years (Le Reverend, Edelson, \& Loret, 2014; Stevenson \& Allaire, 1991; Torola et al., 2012). However, the age at which chewing is mature (i.e., transition of up and down movements of the jaw to rotary movements) is unclear from the literature and is probably later than 3 years old. Thus, children's readiness for a given texture will depend on these developmental changes.

Information regarding the type of food textures accepted by children at a given age during the CF period is quite limited, and variations in food texture acceptance were reported as detailed below. Gisel et al. (1991) investigated the ability of 6- to 24-month-old children to eat foods with different textures: applesauce (puree), viscous orange gelatin and Cheerios ${ }^{\circledR}$ cereal. They reported that children became significantly more efficient (i.e., they required less time and fewer bites) at eating solid food as they aged and that this efficiency was mastered at different ages depending on the texture studied. In addition, there are more reports of food texture preferences during childhood than food texture acceptance (i.e., the ability to process and swallow a food). The seminal work of Szczesniak reported that children prefer food that can be easily manipulated in the mouth (Szczesniak, 1972). More specifically, smooth foods are preferred to hard, spongy and lumpy foods (i.e., foods with pieces in a puree or liquid phase). This finding is supported by behavioural data showing that preferences for complex textures evolve with age. Lundy and colleagues showed that 6- to 12-month-old infants displayed more negative expressions and body movements for lumpy apple puree and diced apples compared to 13- to 24-month-old children (Lundy et al., 1998). To date, only two experimental studies compared the acceptance of different food textures in young children. Blossfeld et al. (2007) showed that 12-month-old children offered chopped and pureed carrots consumed more pureed carrot than chopped carrot. Moreover, mothers reported higher enjoyment of pureed carrot than chopped carrot (Blossfeld, Collins, Kiely, \& Delahunty, 2007). High inter-individual differences in chopped carrot consumption were also reported in this study, suggesting that other factors were involved in food texture acceptance. Recently, another study showed in older children (32-48 months) that modifying the texture of yogurt by adding pieces to it significantly decreased how much yogurt was eaten, whereas modification of the taste or the colour did not change how much yogurt was eaten (Werthmann et al., 2015). Altogether, it is noticeable that within these studies the range of food textures investigated was rather limited compared to what can be proposed to children during the CF period. For example, textures like sticky foods or raw vegetables have not been studied. Texture acceptance of ready-to-eat commercial baby foods has been rarely studied 
(da Costa, Remijn, Weenen, Vereijken, \& van der Schans, 2017) despite the high prevalence of the use of these products in Western countries (Caton, Ahern, \& Hetherington, 2011; Foterek, Hilbig, Kersting, \& Alexy, 2016; Mesch et al., 2014; Schwartz et al., 2013). Whereas the nutritional values of such foods are well-described, little information is actually available on the texture of these products. To our knowledge, only one experimental study characterized the structural properties of baby foods intended for children aged between $4 / 6$ and 24 months (S. Nicklaus et al., 2015). Twenty-five products (7 fruit purees, 18 savoury meal baby foods) available on the French market were studied. These products were smooth purees (from $4 / 6 \mathrm{mo}$ and from $6 \mathrm{mo}$ ) and purees with pieces from 8 mo onwards. The quantity and the size of the pieces tended to increase with age, but large variations were observed between brands and between recipes. The hardness of pieces was found to be independent of the offered age. In another study, it was also shown that baby foods for infants 8 months and older had different levels of texture in different countries in Europe (da Costa et al., 2017). These results reflect the current absence of regulation and very limited guidance regarding the texture of baby food products (S. Nicklaus et al., 2015).

Timely introduction of texture is important for various reasons. Data from the Avon Longitudinal Study of Parents and Children (ALSPAC) showed that children who received lumpy foods before the age of 6 months had less feeding difficulties at 18 months and were less fussy than those who received such foods after 10 months (32\% vs 52\%) (Northstone et al., 2001). Additional data from the same cohort highlighted that 7-year-old children who were introduced to lumpy foods after 10 months had more eating difficulties and ate less fruits and vegetables (H Coulthard et al., 2009).

In this context, the rationale behind the present study was to extend the work of previous studies looking at food texture acceptance during the CF period, by (1) extending the scope of knowledge by assessing a wide variety of textures over a relatively wide age range (6-18 mo); (2) measuring acceptance of each texture, which was given at an earlier age than what most children would be exposed to at home; (3) investigating using a longitudinal set up the link between acceptance and chewing behaviour, in a developmental perspective. Most of the previous results on food texture acceptance were collected cross-sectionally and, as discussed, for a limited range of food textures. Moreover, despite texture acceptance being expected to depend on the development of children's feeding skills, this link has rarely been investigated. Therefore, the aim of the present study was to describe the evolution of food texture acceptance and feeding behaviours between 6 and 10 months, then between 12 and 18 months, in a situation in which the child was challenged (i.e., food textures were offered at an 
earlier age than the usual practice). Based on the literature, we assumed that the acceptance of foods with a specific texture would increase with age and in concordance with the development of chewing behaviour. Likewise, we assumed that children's feeding behaviours, more specifically chewing and sucking, would depend on the texture of a food and would evolve with age.

\section{Materials and Methods}

\subsection{Participants}

This prospective study was conducted at the Centre of Taste and Feeding Behaviour in Dijon, between September 2015 and February 2017. Twenty-five 6-month-old infants were included in the first group (G1) and were observed at 6,8 and 10 months in the lab. The second group $(\mathrm{G} 2, \mathrm{n}=27)$ was composed of 12-month-old children, who were observed at 12, 15 and 18 months at the lab. Participants were recruited via advertisements in health care professionals' consultation rooms, pharmacies and day-care centres. The study was also advertised to the members of two internal consumers databases (PanelSens, CNIL declaration no.1148039; Blédiclub, CNIL declaration $\mathrm{n}^{\circ} 1824320 \mathrm{v} 0$ ), and through the support of an external provider. Eligibility for participation in the study was checked by an initial phone interview, and participants were included if parents had reached legal majority (18 years old), if children were born full-term ( $\geq 37$ gestational weeks), had a birth weight $\geq 2500 \mathrm{~g}$, had not been tubefed since birth, had no chronic diseases or food allergies and were introduced to complementary foods at 5 months $+/-21$ days. This study was conducted according to the guidelines established in the Declaration of Helsinki; the study protocol was approved by the local ethics committee (Comité de Protection de Personnes Est III Nancy, no. 2015/46), and by the national food safety authority (ANSM, file A00323-46). Written informed consent was obtained from both parents.

\subsection{Experimental foods}

The foods selected for the study were chosen in order to explore a wide range of textures for young children aged between 6 and 18 months. The food-texture sets for each follow-up group and each age are presented in Table 1 . The sensory properties of 16 products were determined by a trained panel (see Appendix Tables A.1 and A.2 and Appendix Figures A.1 and A.2 for information); no sensory profiles were obtained for bread and cucumber for practical reasons. The range of food textures included purees (smooth and rough), soft cooked 
pieces (carrot, commercial baby food pasta and shredded chicken), hard foods (defrosted carrot and raw cucumber pieces, commercial baby biscuit and bread), double textures (experimental baby foods recipes and commercial baby food muesli) and sticky foods (banana and cheese). The sensory results showed, among other findings, that the rough carrot puree was distinctly different from the smooth carrot puree and had a mouthfeel characteristic of lumps (mouthfeel for rough puree vs smooth puree: amount of pieces 78 vs 8 ; hardness of pieces 17 vs 1 , size of pieces 12 vs 1). Baby biscuit, pasta and muesli were intended solely for children under three years of age and were sold in the European market. Experimental baby food recipes (BFR) were designed specifically for this study and to represent a wide range of piece sizes (Table 1) and perceived hardness (Appendix Figure A.2). They were created or adapted from current recipes available on the market, but without salt, spices and containing only one vegetable (carrot) in order to limit the impact of taste on children's acceptance. These foods were specifically provided by Bledina/Danone (according to the Directive 2006/125/CE). The choice considered an evaluation of the safety of each food based on internal industrial safety guidelines and approval by the quality manager of Blédina. For each food tested in this study, parents were asked to indicate whether their child had already tried the food or not at each follow-up age. Table 1 presents the percentage of children (G1 and G2) who were already exposed to these foods at each age.

Standardized procedures were applied for each food preparation. Foods were prepared on the day of each session, stored in a cold storage room $\left(4^{\circ} \mathrm{C}\right)$ and placed at room temperature $30 \mathrm{~min}$ before the test session. Before consumption, some foods were heated in a microwave (LG brand) for $10 \mathrm{~s}(650 \mathrm{~W})$. Crusty bread ends (industrial French baguette), baby biscuit, fork-mashed banana and half-slices of banana were prepared during the session to prevent them from drying out or oxidizing.

[Table 1 around here]

\subsection{Evaluation of children's acceptance of foods}

Prior to the beginning of the study, parents were invited to our research centre to receive study materials and instructions. Information regarding the purpose of the study, the type of food textures offered during the lab sessions, and the general design of the study were provided by a trained experimenter. Utensils such as a transparent bowl (Carrefour $\left.{ }^{\circledR}\right)$ and a specific spoon with a shallow and narrow end (Kapitex $\left.{ }^{\circledR}\right)$ were distributed to parents in order to familiarize the child to the utensils used at the lab and to standardize the food presentation. 
For each age, three study sessions per child were planned during the same week, except at 6 months when only two sessions were performed. Children and parents were invited to participate in a meal either for lunch or for an afternoon snack in a room designed specifically for child testing. To control the hunger level of each child, the minimal interval between the last meal/snack and the session was $1 \mathrm{~h} 30 \mathrm{~min}$, and the maximal interval was 3 h. At the beginning of each session, study instructions were checked by asking the parents when the child's last meal/snack had occurred. Information regarding the number of teeth at the time of the session as well as the use of a pacifier before the session was also collected. On the first session at each age, a familiarization phase of 15 min was planned to acclimate the child to the investigator. Before food presentation, parents were asked the child's state of hunger. If he/she was considered very hungry, a few spoons of a simple puree were given to $\mathrm{him} /$ her by the investigator in order to calm hunger. The child was seated in a high chair and fastened with a seat belt. The investigator was seated directly across from the child, in a lower position. This position minimizes the risk of choking (the child's position was determined with a speech-language therapist). The parent was seated next to the investigator and was asked to adopt a neutral face during the session and to not encourage/discourage their child to eat the food. The investigators fed the children instead of parents for three reasons: (1) to standardize the food presentation as much as possible, (2) for safety reason, (3) to avoid that individual differences in parents' behavior would influence the child's reaction during the food presentation.

Nine children refused to be fed by the investigator, and in this situation the parents were shown how to present the food to the child.

Within a session, a maximum of four or five foods with different textures were presented to the child (Table 1), always from the simplest one to the more complex one (i.e., in increasing order of how orally challenging the food was expected to be for children), to prevent the child from getting tired of complex textures too quickly. The foods with similar composition were offered within the same session (e.g., rough carrot puree and rough carrot puree including macaroni). All food textures were placed in a transparent bowl. The bowl was presented to the child for $10 \mathrm{~s}$ before starting the food offering. Then, three spoons of each texture (semi-solids and food pieces) were presented horizontally and removed from the same horizontal plane to allow the child to remove the food with his/her lips. Crusty bread ends and baby biscuits were given whole and not cut into pieces. For these foods, to prevent the detachment of a large piece in the mouth and therefore the risk of choking, the mouth manipulation time was set to $1 \mathrm{~min}$. Between spoons, the investigator checked that the child's 
mouth was empty of food particles and the child could rinse his mouth with mineral water with the utensils usually used at home (bottle, cup, glass). The food offering of a given spoon stopped after 3 consecutive refusals by the child. Food refusal criteria were based on previous studies (Blossfeld et al., 2007; Madrelle et al., 2017). If the child cried or became too upset during the session, the investigator decided to end the session, and the remaining textures were tested during the following test session. Three experimenters performed the test sessions, including a paediatric nurse who was present on site in case of emergencies.

\subsection{Assessment of food acceptance, feeding behaviours and other associated behaviours}

At each spoon presentation, food acceptance (i.e., if the child swallowed the food or not),

feeding behaviours (chewing, sucking), oral discomfort (gagging, coughing/risk of choking, difficulties with the foods) and sensory behaviours shown before the food's consumption (i.e., looking at the food, manipulating the food with fingers and putting the food in the mouth with fingers/spoon) were assessed and registered both by the parent and the investigator using a specific grid (Figure 1). Sucking was defined as a backward-forward jaw movement, with intermittent lip closure and tongue-thrust reflex. Chewing was defined here as up and down movements of the jaw with permanent lips closure to allow an easy assessment of such behaviour by both experimenters and parents. These behaviours were reported in the grid when observed at least 3 times per spoon. Investigators familiarized themselves and agreed on the assessment of behaviours in the grid before the experimental work by observation of videos from pilot test sessions. The parent and the investigator were asked to note the behaviours observed during food consumption (Figure 1). Several behaviours could be rated for a given spoon. The presence of the behaviour was coded as 1 and the absence as 0 . Food liking was assessed right after the three spoons were presented and reported by both the investigator and the parent on a 10-point scale with the anchors "the/my child does not like the food at all" and "the/my child likes the food a lot" (Madrelle et al., 2017).

Acceptance and feeding behaviour assessments were found to be very similar between parents and investigators, therefore only the investigators' assessments are shown in the present article. This restriction allows us to better distinguish what is described objectively from what is perceived by the parents. Behaviours related to oral discomfort were seldom observed in our study and are thus not reported here. For the liking assessment, data from the parents and investigators provided the same conclusions in term of foods; therefore, only the parents' assessments are presented here. 
[Figure 1 around here]

\subsection{Statistical analysis}

Data were analysed using SAS 9.4 software (SAS Institute, Inc, Cary, North Carolina). The binary outcomes $(0 / 1)$, food texture acceptance and feeding behaviours, were expressed as probabilities (AP for acceptance probability, CP for chewing probability and SP for sucking probability). Food texture liking was expressed as the mean $\pm \mathrm{SEM}$.

First, analyses aimed to examine the acceptance, the feeding behaviours and how much the children liked the foods with different textures offered at a given age. For all studied ages, preliminary logistic regressions were performed to assess whether there was a significant effect of the number of spoons on outcome variables. As the analyses did not reveal any significant influence of this factor, data were combined across the spoons for further analyses.

For each group and each age, the acceptance and feeding behaviour probabilities across foods were compared using generalized linear mixed models (proc GLIMMIX procedure). Models were fitted using a binary distribution, logit link, and included food and experimenter as fixed effects and child as a random effect. Pairwise comparisons for categorical predictors were made, with Bonferroni adjustment for multiple comparisons. To compare the liking across foods with different textures at a given age, a generalized linear model (proc GLM) was applied with food and experimenter as fixed effects and child as a random effect. Student-Newman-Keuls (SNK) post hoc tests were used to test liking differences between foods.

Second, to examine the age-related differences in food texture acceptance, feeding behaviours, GLM models stratified on foods were used, with logit link, age class and investigator as fixed effects and child as a random effect. Tukey's HSD grouping was calculated. The liking of foods across ages was compared using a generalized linear model (proc GLM) stratified on foods with age class and child as fixed effects. The StudentNewman-Keuls (SNK) post hoc tests were performed to test the liking differences of a given food between ages. For all statistics analyses, significance was set to $\mathrm{p}<0.05$.

In a third step, all analyses previously described were adjusted for the familiarity with the food. In this case, for each studied food, behavioural (acceptance, chewing and sucking) and liking variables collected over 3 spoons for spoonable foods were averaged by child and by age. Familiarity for a specific food (Table 1) was coded as 1 (child was exposed to the food at 
the age tested in the study) or 0 (the child was not previously exposed). Generalized linear models (proc GLM) were obtained for each food (model: age, familiarity, with random subject effect) and for each age (model: product, familiarity, with random subject effect). Adjusting the analyses with familiarity (when available, see Table 1) was found to seldom impact the results (for analyses by age, conclusions were similar concerning products in $6 / 6$ cases for acceptability, in 4/6 cases for chewing, in 5/6 cases for sucking, and in 6/6 cases for liking; for analyses by products, conclusions were similar concerning products in $17 / 20$ cases for acceptability, in 18/20 cases for chewing, in 19/20 cases for sucking, and in 17/20 cases for liking), therefore for sake of clarity these data are not presented in this paper.

\section{Results}

\subsection{Participant characteristics}

Children's characteristics are presented by age and by follow-up groups in Table 2. One child from G1 and two children from G2 did not complete the follow-study at 8 and 10 months and 15 and 18 months, respectively. Both groups were balanced in term of sex and birth order. Most children had been breastfed, but few were still breastfed by the start of the experiment. Table 1 presents the percentage of children (G1 and G2) who had already been exposed to the studied foods at each age. At 6 months, $92 \%$ of children had already been exposed to smooth carrot puree by the start of the experiment. For the other food textures, the percentages of 6month-old children having been offered the studied foods at the first lab session were much lower $(0-32 \%)$. At 12 months, foods that had been offered to $70 \%$ of children or more included carrot purees (smooth puree: $96 \%$ and rough puree: $89 \%$ ), baby biscuits $(93 \%$ ), experimental baby foods ( $\geq 85 \%)$ and fork-mashed banana (70\%). The children's exposure to the studied foods increased with age, except for muesli, for which the percentage was null or low until 18 mo (12\%), showing that this food was the least used complementary food for this sample of French parents involved in this study. Overall, when comparing child familiarity with a food and the first age at which products were offered in our study, it can be seen in Table 1 that - except for the smooth carrot puree, which had been given to $92 \%$ of the children - the percentages of children already exposed to a specific food before the study were relatively low, varying between 0 (defrosted carrot pieces at $12 \mathrm{mo}$ ) and $38 \%$ (bread at $8 \mathrm{mo}$ ).

[Table 2 around here] 


\subsection{Evolution of children's food acceptance, feeding behaviours and liking between 6 and 10 months}

As shown in Figure 2, food acceptance, feeding behaviours and liking varied across food textures and across ages. From 6 mo on, purees and experimental baby foods (BFR 8 mo and BFR 12 mo A) were highly accepted (AP $\geq 0.9)$, whereas the baby biscuit was the least accepted texture ( $\mathrm{AP}=0.15$, Fig. 2.1). Acceptance of sticky textures increased significantly with age (fork-mashed banana, $F(2,186)=8.57 ; p=0.0003$; cheese, $F(2,181)=12.06 ; p<.0001$ ) from $\mathrm{AP}=0.78$ and $\mathrm{AP}=0.56$ respectively at 6 mo to $\mathrm{AP}=0.98$ and $\mathrm{AP}=0.92$, respectively, at

10 mo. Crusty bread ends and baby biscuit were poorly accepted at 8 mo $(\mathrm{AP}<0.22)$ and were still moderately accepted at $10 \mathrm{mo}$, with probabilities between 0.4 and 0.55 . At 10 mo, muesli was highly accepted $(\mathrm{AP}=0.82)$.

Between 6 and 8 mo, all food textures were processed mostly by sucking ( $\mathrm{SP}>0.75)$, and chewing behaviours were rare $(\mathrm{CP}<0.35$ overall, Fig. 2.2 and 2.3), except for the cooked carrot pieces, which were processed at 8 mo both by sucking and chewing ( $\mathrm{SP}=0.55$ and $\mathrm{CP}=0.6$ respectively). The most marked changes in feeding behaviours occurred between 8 and 10 mo with the strong development of chewing behaviours and a decrease in sucking behaviours. Indeed, the sucking probability decreased significantly with age, especially from 8 to 10 mo for rough carrot puree $(\mathrm{F}(2,187)=12.08 ; \mathrm{p}<.0001)$, rough carrot puree and macaroni $(\mathrm{F}(2,180)=17.08 ; \mathrm{p}<.0001)$, BFR 12 mo A $(\mathrm{F}(1,118)=24.07 ; \mathrm{p}<.0001)$, cooked carrot pieces $(\mathrm{F}(1,104)=11.70 ; \mathrm{p}=0.0009)$, fork-mashed banana $(\mathrm{F}(2,186)=11 ; \mathrm{p}<.0001)$, cheese $(F(2,181)=11.77 ; p<.0001)$ and baby biscuit $(F(2,45)=5.54 ; p=0.007)$. There was a significant effect of age on the chewing probability for a majority of foods: rough carrot puree $(F(2,189)=19.41 ; p<.0001)$, cooked carrot pieces $(F(1,104)=13.15 ; p=0.0004)$, fork-mashed banana $(\mathrm{F}(2,188)=18.15 ; \mathrm{p}<.0001)$, cheese $(\mathrm{F}(2,181)=19.46 ; \mathrm{p}<.0001)$, baby biscuit $(F(2,43)=7.69 ; p=0.0014)$, crusty bread ends $(F(1,22)=6.71 ; p=0.0167)$, rough carrot puree and macaroni $(\mathrm{F}(2,180)=22.10 ; \mathrm{p}<.0001)$, BFR $8 \mathrm{mo}(\mathrm{F}(1,110)=15.24 ; \mathrm{p}=0.0002)$, and BFR $12 \mathrm{~A}$ mo $(\mathrm{F}(1,118)=12.97 ; \mathrm{p}=0.0005)$.

Parental assessments of infant's food texture liking (Fig. 2.4) differed by food texture at the three ages: 6 mo $(F(6,423)=29.17 ; p<0.0001), 8 \mathrm{mo}(F(9,585)=10.70 ; p<0.0001)$ and $10 \mathrm{mo}(\mathrm{F}(9,581)=13.46 ; \mathrm{p}<0.0001)$. Between 6 and $10 \mathrm{mo}$, the average liking scores for all food textures varied from 5 to 9. Carrot purees were the most liked texture from 6 mo (liking score $>9$ ), with cheese being the least liked (liking score=6). There was a significant age effect on liking for the rough carrot puree $(\mathrm{F}(2,190)=12.47 ; \mathrm{p}<0.0001)$, cooked carrot pieces 
$(F(1,111)=34.75 ; p<0.0001)$, fork-mashed banana $(F(2,190)=24.61 ; p<0.0001)$, cheese $(\mathrm{F}(2,187)=50.13 ; \mathrm{p}<0.0001)$, crusty bread ends $(\mathrm{F}(1,23)=4.44 ; \mathrm{p}=0.0462)$, rough carrot puree and macaroni $(F(2,184)=21.9 ; \mathrm{p}<0.0001)$, BFR $8 \mathrm{mo}(\mathrm{F}(1,119)=63.30 ; \mathrm{p}<0.0001)$ and $\mathrm{BFR}$ 12 mo A $(F(1,119)=30.52 ; p<0.0001)$. These food textures were significantly more liked with age. Notably at $8 \mathrm{mo}$, hard food textures such as baby biscuit and crusty bread ends were the least accepted food textures (Fig. 2.1). Nevertheless, they were highly liked (liking scores $>8$; Fig. 2.4).

[Figure 2 around here]

\subsection{Evolution of children's food acceptance, liking and feeding behaviours between 12 and 18 months}

From 12 mo on, soft cooked pieces (shredded chicken and cooked carrot pieces) were wellaccepted $(\mathrm{AP}>0.6)$, except pasta $(\mathrm{AP}=0.3)$. However, pasta acceptance increased significantly $(\mathrm{F}(2,196)=11.55 \mathrm{p}<.0001)$ until 18 months $(\mathrm{AP}=0.73)$ (Fig. 3.1). Sticky textures were moderately accepted at 12 mo (half slice of banana $\mathrm{AP}=0.54$; cheese $\mathrm{AP}=0.72$ ); the acceptance of half slices of banana increased significantly until 18 mo $(F(2,191)=8.85$; $\mathrm{p}=0.0002$ ). Among hard textures, baby biscuit and crusty bread ends were well-accepted from 12 mo ( $\mathrm{AP}>0.65$ ), whereas vegetable pieces (raw cucumber and defrosted carrot) were poorly accepted $(\mathrm{AP}<0.4)$. The acceptance of the following food textures increased sharply from 15 mo: pasta $(F(2,196)=11.55 ; \mathrm{p}<.0001)$, half slice of banana $(F(2,191)=8.85 ; \mathrm{p}=0.0002)$, crusty bread ends $(\mathrm{F}(2,48)=3.98 ; \mathrm{p}=0.025)$, biscuit $(\mathrm{F}(2,48)=3.84, \mathrm{p}=0.028)$ and defrosted carrot pieces $(F(2,191)=3.94 ; p=0.02)$. The acceptance of these foods remained stable between 15 and 18 mo. BFR 12 mo B and BFR 18 mo were highly accepted at the two age classes $(\mathrm{AP}>0.8)$. Surprisingly, a significant decrease in the acceptance of rough carrot puree with shredded chicken was observed between 15 and $18 \mathrm{mo}(\mathrm{F}(2,197)=5.84 ; \mathrm{p}=0.0034)$. Although not significant ( $\mathrm{p}>0.08)$, a similar trend was observed for the muesli.

Between 12 and 18 mo, foods were essentially processed by chewing, and sucking was rare ( $\mathrm{SP}<0.1$; Fig. 3.2 and 3.3), except for the baby biscuit and bread at $12 \mathrm{mo}(\mathrm{SP}=0.46$ and $\mathrm{SP}=0.28$, respectively). The probability of chewing all food textures were high at $12 \mathrm{mo}$ and remained stable until $15 \mathrm{mo}$. At $12 \mathrm{mo}$, the probability of chewing hard textures such as crusty bread ends, baby biscuit or cooked pieces were within the same range as observed at 10 mo in the younger group of children (G1). 
There was a significant effect of age on chewing probability in the case of pasta $(F(2,196)=11.13 ; p<0.0001)$, cheese $(F(2,196)=3.25 ; p=0.041)$, half-slices of banana $(F(2,191)=9.36 ; p<0.0001)$ and defrosted carrot pieces $(F(2,191)=4.79 ; p=0.009)$. Children were more likely to use chewing to process these foods as they got older. Interestingly for muesli, the chewing probability decreased significantly with age $(F(2,187)=5.58 ; p=0.004)$, and the same tendency was observed for rough carrot puree with shredded chicken $(\mathrm{F}(2$, 197) $=3.04 ; \mathrm{p}=0.0503$ ).

At 1 year of age, crusty bread ends and baby biscuit were the most liked textures. Pasta, defrosted carrot and raw cucumber pieces were the least liked textures (Fig. 3.4). There was a significant effect of age on the liking of cooked carrot pieces $(F(2,196)=7.76$; $\mathrm{p}=0.0006)$, pasta $(\mathrm{F}(2,202)=26.82 ; \mathrm{p}<.0001)$, defrosted carrot pieces $(\mathrm{F}(2,192)=15.21$; $\mathrm{p}<.0001)$, cheese $(\mathrm{F}(2,222)=7.35 ; \mathrm{p}=0.0008)$, half-slices of banana $(\mathrm{F}(2,176)=26.32$; $\mathrm{p}<.0001)$, BFR $12 \mathrm{mo} \mathrm{B}(\mathrm{F}(1,119)=20.71 ; \mathrm{p}<.0001)$ and $\mathrm{BFR} 18 \mathrm{mo}(\mathrm{F}(1,111)=11.02$; $\mathrm{p}=0.0012$ ). As observed for acceptance, the liking of rough carrot puree with shredded chicken significantly decreased with age $(F(2,198)=4.08 ; p=0.018)$. A similar trend was observed for the muesli.

[Figure 3 around here]

\section{Discussion}

To our knowledge, this study is the first longitudinal study to assess the evolution of food texture acceptance and feeding behaviours during the complementary feeding period with measurements taking place in a fully controlled laboratory setting. Typical for our study is also that when first introduced to the experimental foods, most of the children were not familiar with the textures of these foods, except for the smooth pureed foods, which means that the chosen food textures were potentially challenging for children. Nevertheless, texture acceptance probabilities were generally high ( $>0.6)$ right from the first assessment, except for crusty bread ends, biscuit and cheese in the younger age group and except for pasta, raw vegetables, banana and cheese in the older age group.

When comparing at which ages acceptance probabilities were high $(>0.6)$ with ages at which these food textures had been introduced by the majority of the parents $(>0.5)$, three situations were possible: 1 . The majority of parents introduced foods later than what acceptance data suggest is possible, 2 . The majority of parents introduced foods at about the 
same age as what the acceptance data suggest is possible, 3 . The majority of parents introduced foods earlier than what the acceptance data suggest is possible. Situation 1 was observed for the following textures: rough carrot puree, cooked carrot pieces, shredded chicken, BFR 8 mo, BFR 12 mo, BFR 18 mo, muesli, fork-mashed banana, and soft cheese. Situation 2 was observed for smooth carrot puree, pasta, and half-slices of banana. Situation 3 was observed for baby biscuit and crusty bread ends. Situation 1 suggests that these foods can be introduced earlier than what is current practice, situation 2 suggests that parents are introducing these foods when children are able to handle the texture of these foods. The foods in situation 3 suggest that these foods may be given to children as foods for children to bite and suck on, for children to practice their biting skills, which means that acceptance, in our study defined as the ability to swallow within the time frame of the study, is not important.

\subsection{Feeding behaviour development between 6 and 18 months}

Consistent with our hypothesis, between 6 and 18 months, feeding behaviours evolved both with age and with the texture of foods. We observed drastic changes in the development of feeding behaviours between 6 and 10 months. Six-month-old children only processed food by sucking. At 8 months, chewing behaviour emerged and was established for most children by 10 months old. Chewing then continued to develop until 18 months for hard foods (except cucumber sticks) and double textures (except muesli). In parallel, sucking behaviour decreased between 6 and 10 months and became rare from 12 months on for all food textures. At 10 months, most children used both sucking and chewing to process rough puree, forkmashed banana, biscuit and double textures, suggesting that this period is a key developmental stage in the oral processing of food textures. Altogether, these results showed that the development of feeding skills necessary to process solid foods is learnt during the first year of life and continues to develop during the second year. Our findings are in agreement with the early observation of Gisel, who reported marked changes in chewing efficiency (measured as chewing duration and number of chewing bites) between 6 and 10 mo of age, especially for solid (Cheerios(C) and viscous (orange juice gelatine) textures (Gisel, 1991). Our results also showed that children's feeding behaviours varied as a function of food texture. Smooth purees were only processed by sucking at both ages studied (at 6 and $8 \mathrm{mo}$ ). At 10 mo, the probability of chewing cooked carrot pieces was higher than the probability of chewing fork-mashed banana. At the same age, fork-mashed banana was more frequently sucked than cooked carrot pieces. These observations were in line with Gisel's study, which 
also showed that up to 10 mo, children tend to suck on applesauce but munch on Cheerios ${ }^{\circledR}$ cereal. This author hypothesized that children are processing the food using the method requiring the least effort.

Gisel concluded from her study that munching, i.e., immature chewing, was firmly established at 8 months old. This observation cannot be concluded from our data. Indeed, in our study, the probability of observing chewing behaviour in 8-month-old children was approximately $30 \%$ for solid foods, and our results indicate that chewing becomes a common behaviour only at a later age (10 to $12 \mathrm{mo}$ ). The discrepancy between both studies can be explained by the fact that the products tested were not the same and that both studies were run in different countries. A possible explanation is that the parental feeding practices are different between both countries, i.e., it may be that rougher and more difficult textures are introduced later in France (Bocquet \& Vidailhet, 2015; S. Nicklaus et al., 2015), and therefore chewing may develop more slowly (as an effect of exposure).

\subsection{Food texture acceptance during infancy}

With regards to food acceptance, we observed similar evolution patterns by texture type. Therefore, we discuss the results by type of food texture. A top-line summary for the acceptance of each food-texture type as a function of age is given in Figure 4.

[Figure 4 around here]

Not surprisingly, pureed textures were the most accepted texture for all ages. In our sample, more than $90 \%$ of the children in both groups had been offered smooth carrot puree before the study (Table 1). This finding was in line with a previous qualitative study reporting that carrot puree is generally the first food given to infants at the beginning of CF in France (Schwartz et al., 2013). Therefore, the familiarity with this texture may have contributed to the high acceptance observed. It is worth noting that the rough carrot puree with soft lumps offered in our study was also highly accepted from 6 months onward, whereas this texture had not been offered very much to children at 6 months (32\%). Thus, rough purees with soft lumps are clearly very well-accepted by infants at 6 months, which suggests that this texture may also be accepted by infants slightly before 6 months. Recommending the introduction of this type of texture before 6 months may therefore be considered. It would be helpful for their 
oral development because it solicits more tongue movements (Mason, Harris, \& Blissett, 2005).

Soft cooked pieces were highly accepted from 8 months onward. Similar results were found in a recent French survey where mothers were asked to assess their child's acceptance level of foods with different textures. This finding was also observed in a US study: small pieces of foods were accepted from 8-9 mo (Carruth \& Skinner, 2002). In our study, the probability of chewing soft cooked pieces at 8 mo was high, which suggests that infants were sufficiently developed orally to cope with soft cooked pieces from 8 mo onward. Together with the chewing behaviour, children probably also acquired enough tongue mobility to press a food against the palate (Le Reverend et al., 2014; Stevenson \& Allaire, 1991). Moreover, the low number of teeth in children at 8 months in our sample (1.25) suggests that the successful acceptance of soft cooked pieces did not require the help of teeth. With regard to liking, we observed that the children's liking for cooked pieces (chicken and cooked carrot pieces) was high and increased with age for cooked carrot pieces compared to raw vegetable pieces. Our results suggest that the type of food preparation influenced the liking of foods, and could therefore influence their acceptance. Zeinstra et al showed in older children (4-12 years) that carrot and French beans cooked by boiling or steaming were preferred over mashed or fried vegetables (Zeinstra, Koelen, Kok, \& de Graaf, 2010). The authors explained this effect by the familiarity with the mode of food preparation; children preferred vegetables cooked with a method to which they were accustomed.

The sticky textures used in our study were well-accepted and liked by children between 6 and 18 months. This finding is contrary to the previous observation of Szczesniak, in which it was noted that sticky and slimy textures were generally disliked by children because of their lack of control over this texture in the mouth (Szczesniak, 2002). However, it could be noted that at 6 months, the probability of accepting sticky textures was lower than at 8 and 10 months. Likewise, the probability of accepting sticky textures was lower at 12 months than at 15 and 18 months. This finding is most likely due to lack of familiarity. At these two ages, children were not familiar with the textures of cheese and banana presented in this study. The low acceptance of cheese at 12 months is especially surprising, as the current French recommendation advise the introduction of cheese in small pieces from 8-10 months (INPES, 2005). For bananas, at 12 months, children were exposed to the taste but not to the texture in pieces.

We found that double textures, in our study purees with soft lumps, were highly accepted and liked at all ages, although some of these products were offered on the market for 
older children. Our results differed from those of previous studies that showed that lumps in a preparation were a difficult texture for children during the $\mathrm{CF}$ period and were quite often rejected (H. Coulthard \& Harris, 2003; Lundy et al., 1998; Werthmann et al., 2015). In particular, it was found that a significant proportion of infants $(23 \%)$ have difficulties with foods containing pieces (H. Coulthard \& Harris, 2003). Another study found, in older children 32-48 mo, that the addition of fruit pieces in yoghurt caused a significant decrease in yoghurt intake compared to smooth yoghurt (Werthmann et al., 2015). Such difficulties seem to be related to insufficient oral skills to separate in the mouth lumps that are big enough to trigger the gag reflex and need to be moved to the side of the mouth, from the rest of the mass that can be swallowed using a liquid swallow (Harris \& Mason, 2017; Mason et al., 2005). Therefore, it seems that our products were sufficiently homogenous (soft pieces in thick mass), and thus children did not need to separate pieces from the rest of the mass before swallowing. The sensory profiling confirmed this observation: experimental baby foods recipes were judged by adult panellists to have a thick texture.

Muesli is a different case; it has a double texture or perhaps multiple textures with more contrast in viscosity between the liquid phase (milk) and the hard pieces. It has relatively low probabilities of acceptance and texture liking. Interestingly, its acceptance tended to decrease with age along with its liking. As explained above, the disliking of such texture could be related to the oral discomfort induced by a gritty tactile sensation or because of the children's difficulty processing the two different phases. This finding was demonstrated in older children (32-48 mo): the consumption of yoghurt with raspberry pieces was lower than the consumption of yoghurt without pieces (Werthmann et al., 2015). In addition, children from our sample had not been exposed to this food until 15 months, which can explain its initial low acceptance level. A possible explanation for the decrease in acceptance and liking of muesli is that the 6-12 month period is a critical period for the introduction of textures (H Coulthard et al., 2009; Harris \& Mason, 2017). This fact could mean that the longer a texture is introduced after 12 months, the less it is accepted.

Among the hard textures tested in our study, different acceptance patterns over age were observed between foods. The acceptance of baby biscuit and crusty bread ends increased gradually between 6 and 18 months. At a younger age, biting force is insufficient to break down the food and swallow it; the sucking strategy was mainly used by children from our sample to process and consume these foods. With age and the development of chewing behaviours, the biscuit was better processed and ultimately highly accepted. The low acceptance of bread and biscuit at younger ages could also be explained by their presentation. 
Indeed, we fixed the processing time in the mouth for these foods, which may have been too short to observe the children's food swallowing. Considering the size and format of these foods, additional criteria (e.g., number of bites) should be taken into account to assess their acceptance by children.

For all foods but one, liking and acceptance followed the same pattern, i.e., when liking increased, acceptance increased or vice versa. This may be a reflection of how parents assess liking: if a parent sees the child accepts a food, it indicates that the child likes that food. However, the exception was the biscuit: liking was high right from the start, but acceptance clearly increased with age. In this case parents were able to evaluate liking independently from acceptance. This pattern showed that a food that is hard to manipulate in the mouth is not necessarily disliked.

In addition, we observed that raw vegetable pieces and pasta had similar acceptance and liking patterns despite their different textural properties. Considering their textural differences, we did not expect such similarity in behaviours between these two foods. In addition, between 12 and 18 months, these foods were the least accepted textures, suggesting that they were still challenging for children.

In this study we focused on the textural properties of the foods and their relationships with children's oral processing behaviours (chewing/sucking), acceptance (ability to swallow the food) and liking (determined by the parents). The foods were chosen to represent a wide range of textural properties and we paid attention to avoid strong tastes and flavours. For example, salt and spices were avoided in the experimental baby foods; bitter/sour tastes were avoided in the fruits and vegetables (carrot, cucumber and banana); the cheese ripening was controlled and limited to avoid strong taste and flavour. However we cannot rule out that the tastes and the flavours (or other sensory dimensions, e.g. visual) of the chosen foods could have impacted on the present results. Indeed, it is well known that these dimensions can play a role in food acceptance in children (Schwartz et al., 2017). On the one hand, in our study, analysing the effect of texture in the absence of taste/flavour variation can be made when looking at the carrot products (smooth puree, rough puree, cooked pieces and defrosted pieces). When comparing these products, the evolution of acceptance as a function of the texture and the child's age is clearly observable. On the other hand, other products presented in our study have comparable texture but a different taste/flavour. This is the case for all baby food recipes, the sticky pieces (banana and cheese) and hard pieces (defrosted carrot and cucumber). In each of these cases, it can be seen that acceptance and the liking are quite similar at a given age and that they follow a similar evolution with age. We therefore decided 
to group products according to their texture in our top-line summary in Figure 4. Finally, we cannot rule out that the familiarity with specific types of textures or with specific tastes/flavours may have altered acceptance in individual cases; however we did not collect this specific information, since we only assessed familiarity at the food level, for each type of texture. However, as mentioned in the statistics section, the inclusion of familiarity as covariate hardly changed the results, and was therefore not further evaluated.

\subsection{Strengths and limitations}

The first strength of this study lies with the design; it is the first longitudinal study describing the acceptance of a wide range of different food textures during the CF period. Even if the follow-up periods were of short duration in both groups of children, we observed differences in acceptance and feeding behaviours across food textures and ages, showing that the method is sensitive enough to reveal variability in children's acceptance of foods with different textures.

Our assessment of the food texture acceptance and feeding behaviours was performed on a triplet of spoons or during a fixed period of time for foods given as a unit. This system allowed a detailed evaluation of behaviours, but it was impossible to use ad libitum intake data considering the short amount of time per food and the large number of food textures tested. It may be useful to assess whether the acceptance of the first spoons predicts acceptance of the whole portion. A previous study showed that for some commercial baby foods, acceptance during the first spoon predicted acceptance at the end of the meal (Madrelle et al., 2017), but this finding remains to be confirmed for other textures. In addition, as discussed above, we cannot rule out that the acceptance and liking of the studied foods were affected by characteristics other than texture alone. Results may have been modulated by variation in products' taste and flavour, either directly or via taste-flavour-texture cross-modal interactions. Therefore, to better control for these aspects, future investigations should focus on different texture variants of a given food or model foods for which texture and flavour are modified independently.

\section{Conclusion}

This is the first study to assess the acceptance of a wide variety of foods with different textures during early childhood, more specifically in the period of 6 to 18 months. Acceptance of most textures was evaluated at an age earlier than the age at which children received each 
texture for the first time at home. The results showed that children accepted some textures at an earlier age than their parents' feeding practices: rough carrot puree, cooked carrot pieces, shredded chicken, BFR 8 mo, BFR 12 mo, BFR 18 mo, muesli, fork-mashed banana, and soft cheese. Pureed textures and baby food recipes were the most accepted textures for all ages. Soft cooked pieces were highly accepted from 8 months, as were sticky textures. The acceptance of hard and raw pieces increased progressively between 6 and 18 months and goes together with the emergence of chewing behaviour. The results could be used to develop guidelines for the introduction and progression of food textures during complementary feeding in accordance with children's acceptance and feeding skills development. These guidelines could encourage the introduction of pieces earlier than the current practices in France, during the second half of the first year, which is not the case at present. Moreover, the results could help food industry when designing new developmentally appropriate foods.

\section{Authors' contributions}

LD, CT, AM, HW, MD and SN designed the research. LD designed the study, collected data, completed the statistical analysis, and drafted the manuscript. The manuscript was then critically reviewed by CT and SN, then revised by CT, AM, HW, MD and SN. All of the authors are responsible for the study findings. All of the authors read and approved the final manuscript.

\section{Acknowledgement}

We gratefully acknowledge Mieke Vader (Danone Nutricia Research) for providing the sensory profiling results, Floée Schultz and Emilie Szleper (INRA) for help conducting the experimental measurements, and Christophe Martin, Fabienne Bouillot and Françoise Durey of the ChemoSens platform (INRA) for their global support. This work was supported by a grant from Blédina, S.A., and by the support of the Research and Technology National Association (ANRT).

\section{References}

Blossfeld, I., Collins, A., Kiely, M., \& Delahunty, C. (2007). Texture preferences of 12-month-old infants and the role of early experiences. Food Quality and Preference, 18(2), 396-404. 
Bocquet, A., \& Vidailhet, M. (2015). Nutri-Bébé 2013 Study Part 2. How do French mothers feed their young children? Archives de pediatrie, 22(10, Supplement 1), 10S17-10S19.

Carruth, B., \& Skinner, J. (2002). Feeding Behaviors and Other Motor Development in Healthy Children (2-24 Months). Journal of the American College of Nutrition, 21(2), 88-96.

Carruth, B., Ziegler, P., Gordon, A., \& Hendricks, K. (2004). Developmental milestones and selffeeding behaviors in infants and toddlers. Journal of the American Dietetic Association, 104(1), S51-S56.

Caton, S. J., Ahern, S. M., \& Hetherington, M. M. (2011). Vegetables by stealth. An exploratory study investigating the introduction of vegetables in the weaning period. Appetite, 57, 816-825.

Coulthard, H., \& Harris, G. (2003). Early food refusal: The role of maternal mood. Journal of Reproductive and Infant Psychology, 21(4), 335-345.

Coulthard, H., Harris, G., \& Emmett, P. (2009). Delayed introduction of lumpy foods to children during the complementary feeding period affects child's food acceptance and feeding at 7 years of age. Maternal and Child Nutrition, 5(1), 75-85.

da Costa, S. P., Remijn, L., Weenen, H., Vereijken, C., \& van der Schans, C. (2017). Exposure to texture of foods for 8-month-old infants: Does the size of the pieces matter? J Texture Stud, 27(10), 12271.

Fewtrell, M., Bronsky, J., Campoy, C., Domellöf, M., Embleton, N., Fidler Mis, N., . . Molgaard, C. (2017). Complementary Feeding: A Position Paper by the European Society for Paediatric Gastroenterology, Hepatology, and Nutrition (ESPGHAN) Committee on Nutrition. Journal of Pediatric Gastroenterology and Nutrition, 64(1), 119-132.

Foterek, K., Hilbig, A., Kersting, M., \& Alexy, U. (2016). Age and time trends in the diet of young children: results of the DONALD study. [journal article]. European Journal of Nutrition, 55(2), 611-620. doi: 10.1007/s00394-015-0881-6

Gisel, E. G. (1991). Effect of food texture on the development of chewing of children between six months and two years of age. [Research Support, Non-U.S. Gov't]. Dev Med Child Neurol, 33(1), 69-79.

Harris, G., \& Coulthard, H. (2016). Early Eating Behaviours and Food Acceptance Revisited: Breastfeeding and Introduction of Complementary Foods as Predictive of Food Acceptance. Current Obesity Reports, 5(1), 113-120.

Harris, G., \& Mason, S. (2017). Are There Sensitive Periods for Food Acceptance in Infancy? Current Nutrition Reports, 6(2), 190-196. doi: 10.1007/s13668-017-0203-0

INPES. (2005). PNNS - La santé vient en mangeant - Le guide parents 0-3 ans (pp. 40). Paris: Institut National de Prévention et d'Education pour la Santé.

Lanigan, J. A., Bishop, J. A., Kimber, A. C., \& Morgan, J. (2001). Systematic review concerning the age of introduction of complementary foods to the healthy full-term infant. European Journal of Clinical Nutrition, 55(5), 309-320. 
Le Reverend, B. J., Edelson, L. R., \& Loret, C. (2014). Anatomical, functional, physiological and behavioural aspects of the development of mastication in early childhood. The British journal of nutrition, 111(3), 403-414.

Lundy, B., Field, T., Carraway, K., Hart, S., Malphurs, J., Rosenstein, M., . . Hernandez-Reif, M. (1998). Food texture preference in infants versus toddlers. Early Child Development Care, $146,69-85$.

Madrelle, J., Lange, C., Boutrolle, I., Valade, O., Weenen, H., Monnery-Patris, S., . . Nicklaus, S. (2017). Development of a new in-home testing method to assess infant food liking. Appetite, 113, 274-283. doi: http://dx.doi.org/10.1016/j.appet.2017.03.002

Mason, S. J., Harris, G., \& Blissett, J. (2005). Tube Feeding in Infancy: Implications for the Developmentof Normal Eating and Drinking Skills. [journal article]. Dysphagia, 20(1), 46-61. doi: 10.1007/s00455-004-0025-2

Mesch, C. M., Stimming, M., Foterek, K., Hilbig, A., Alexy, U., Kersting, M., \& Libuda, L. (2014). Food variety in commercial and homemade complementary meals for infants in Germany. Market survey and dietary practice. Apptite, 76, 113-119.

Nicklaus. (2016). Complementary Feeding Strategies to Facilitate Acceptance of Fruits and Vegetables: A Narrative Review of the Literature. International Journal of Environmental Research and Public Health, 13(11), 1160.

Nicklaus, S., Demonteil, L., \& Tournier, C. (2015). Modifying the texture of foods for infants and young children. In R. Chen J, eds (Ed.), Modifying food texture Volume 2: Sensory analysis, consumer requirements and preferences. Cambridge, England: Woodhead Publishing Limited.

Northstone, K., Emmett, P., Nethersole, F., \& Team, A. S. (2001). The effect of age of introduction to lumpy solids on foods eaten and reported feeding difficulties at 6 and 15 months. Journal of Human Nutrition and Dietetics, 14(1), 43-54.

Schwartz, C., Madrelle, J., Vereijken, C., Weenen, H., Nicklaus, S., \& Hetherington, M. (2013). Complementary feeding and "donner les bases du goût" (providing the foundation of taste). A qualitative approach to understand weaning practices, attitudes and experiences by French mothers. Appetite, 71, 321-331.

Schwartz, C., Vandenberghe-Descamps, M., Sulmont-Rossé, C., Tournier, C., \& Feron, G. (2017). Behavioral and physiological determinants of food choice and consumption at sensitive periods of the life span, a focus on infants and elderly. Innovative Food Science \& Emerging Technologies. doi: https://doi.org/10.1016/j.ifset.2017.09.008

Stevenson, R. D., \& Allaire, J. H. (1991). The development of normal feeding and swallowing. Pediatric clinics of North America, 38(6), 1439-1453.

Stolovitz, P., \& Gisel, E. G. (1991). Circumoral movements in response to three different food textures in children 6 months to 2 years of age. [Research Support, Non-U.S. Gov't]. Dysphagia, 6(1), $17-25$. 
Szczesniak, A. (1972). Consumer awareness of and attitudes to food texture. II. Children and teenagers. Journal of Texture Studies, 3, 206-217.

Szczesniak, A. (2002). Texture is a sensory property. Food Quality and Preference, 13(4), 215-225.

Torola, H., Lehtihalmes, M., Yliherva, A., \& Olsen, P. (2012). Feeding skill milestones of preterm infants born with extremely low birth weight (ELBW). Infant Behavior \& Development, 35 , 187-194.

Werthmann, J., Jansen, A., Havermans, R., Nederkoorn, C., Kremers, S., \& Roefs, A. (2015). Bits and pieces. Food texture influences food acceptance in young children. Appetite, 84, 181-187.

Zeinstra, G. G., Koelen, M. A., Kok, F. J., \& de Graaf, C. (2010). The influence of preparation method on children's liking for vegetables. Food Quality and Preference, 21(8), 906-914. doi: http://dx.doi.org/10.1016/j.foodqual.2009.12.006 
(a)

\begin{tabular}{|l|l|l|l|l|l|l|l|l}
\hline \multicolumn{2}{|l|}{ When the food is presented } & \multicolumn{2}{l}{ When the food is in the mouth } \\
\hline $\begin{array}{l}\text { Looks at } \\
\text { the food }\end{array}$ & $\begin{array}{l}\text { Handles } \\
\text { with } \\
\text { fingers }\end{array}$ & $\begin{array}{l}\text { Puts the food in } \\
\text { mouth with } \\
\text { fingers or spoon }\end{array}$ & $\begin{array}{l}\text { Refuses } \\
\text { the food }\end{array}$ & $\begin{array}{l}\text { Has } \\
\text { difficulties } \\
\text { with the food }\end{array}$ & Gags & $\begin{array}{l}\text { Coughs, } \\
\text { risk of } \\
\text { choking }\end{array}$ & $\begin{array}{l}\text { Sucks } \\
\text { the food }\end{array}$ & $\begin{array}{l}\text { Chews } \\
\text { the food }\end{array}$ \\
\hline S1 & & & & & & & & \\
S3 & & & & & & & & \\
\hline
\end{tabular}

(b)

1

O $\quad$ O $\quad$ O

O

O

My child doesn't

like the food at

all

Figure 1: Evaluation grid used to assess sensory behaviours, feeding skills and acceptance for the triplet of spoons with one row per spoon number (a) and scale used to evaluate children's liking at the end of the triplet of spoons assessed (b). The behaviour "has difficulties with the food" was defined as the child removes the food from the mouth with fingers; or takes time to manipulate the food in the mouth; or keeps the food in the mouth during a long time and does nothing with it. 
(1) Food texture acceptance probability (AP)

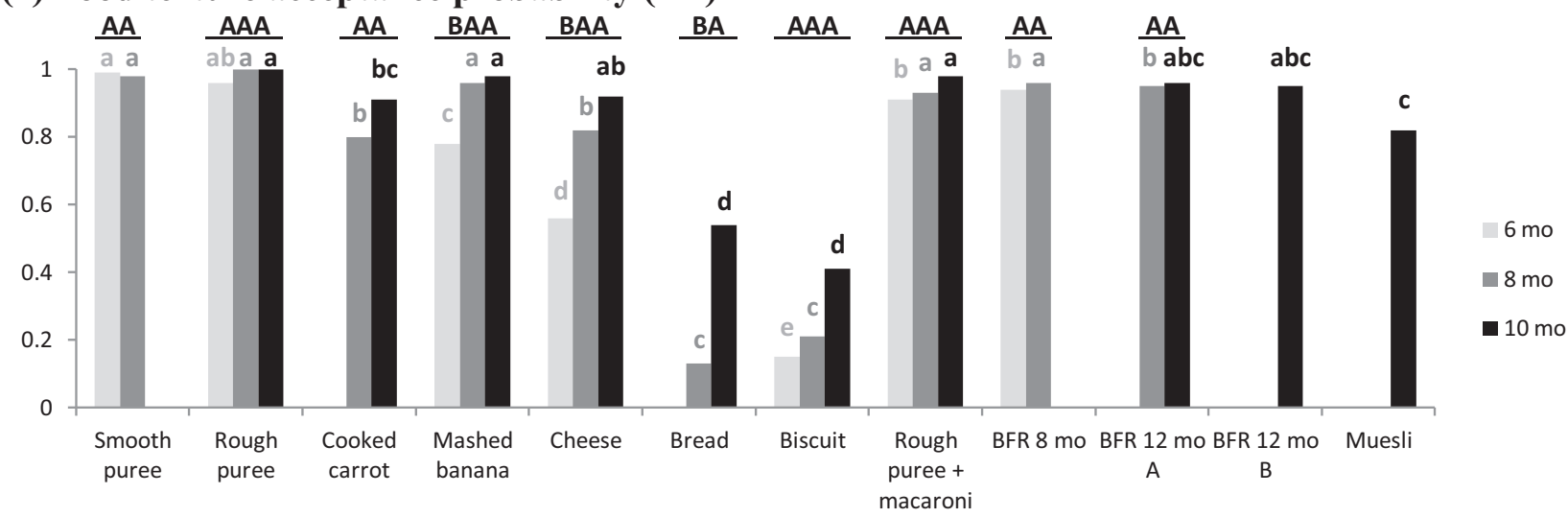

(2) Sucking probability (SP)

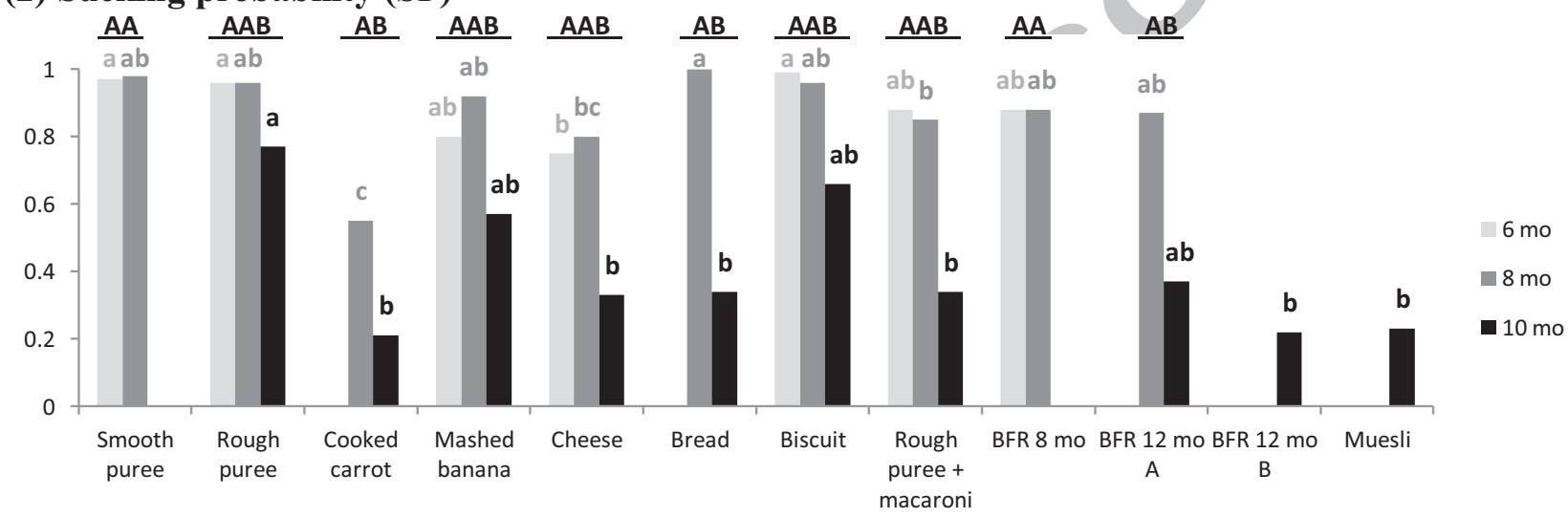

(3) Chewing probability (CP)

AA CBA BA CBA CBA BA BAA CBA BA BA

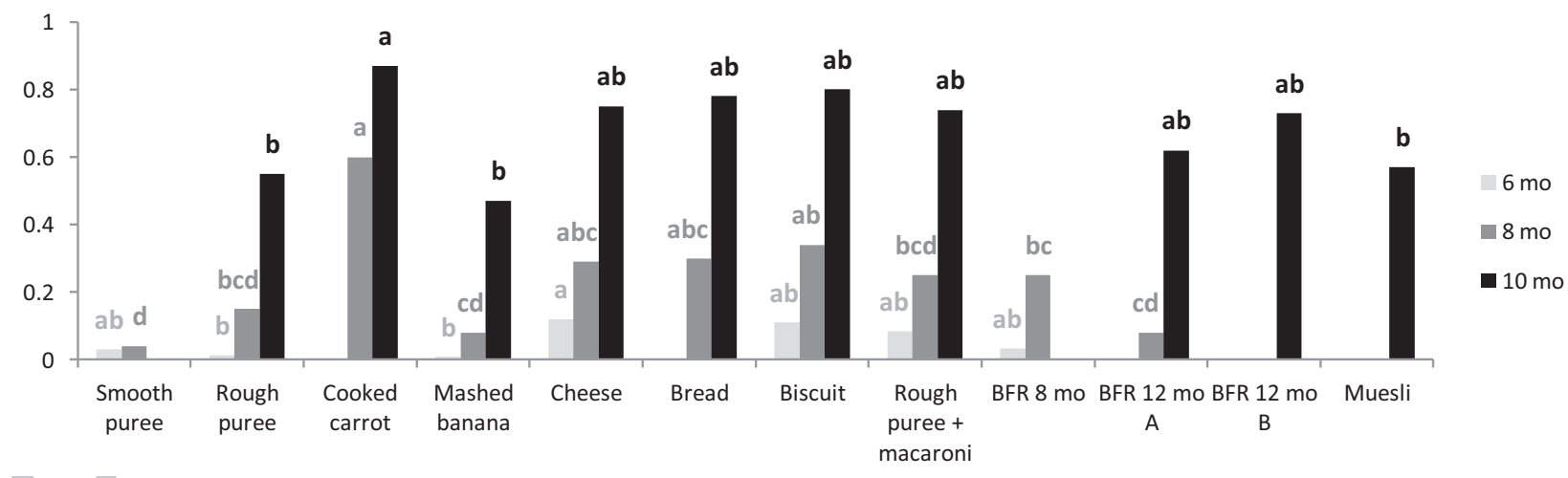

(4) Food texture liking

AA BAA BA CBA BAA BA AAA BAA BA BA 


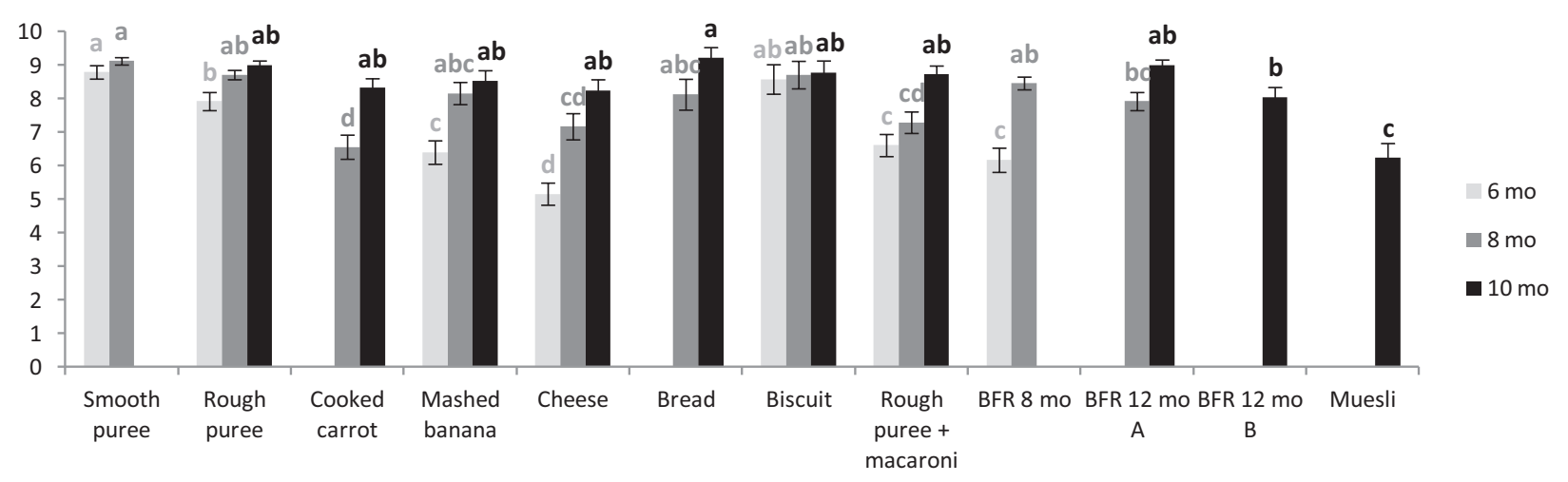

Figure 2. Estimated probabilities of acceptance (1), sucking (2), chewing (3) and mean $( \pm$ SEM) liking scores $(4)$ of each food texture at each age in the first group of children $(6,8$ and 10 months). For a given age, food-texture related differences in probabilities were assessed using Bonferroni correction: foods with the same lowercase letter are not significantly different $(\mathrm{p}<0.05)$. For a given food texture, age-related differences in probabilities were assessed by the Tukey test and were represented by letters in uppercase. For the liking, age-related differences in liking were assessed with the Student-NewmanKeuls test. Ages with the same letters are not significantly different $(p<0.05)$. The range of food textures included carrot purees (smooth puree and rough puree), soft cooked pieces (cooked carrot pieces, commercial baby food pasta and shredded chicken), hard foods (commercial baby biscuit and crusty bread ends), double textures (rough puree \& macaroni, experimental baby foods recipes BFR 8mo, BFR $12 \mathrm{mo}$ A, BFR $12 \mathrm{mo} \mathrm{B}$, and commercial baby food muesli) and sticky foods (mashed banana and cheese). 
(1) Food texture acceptance probability (AP)

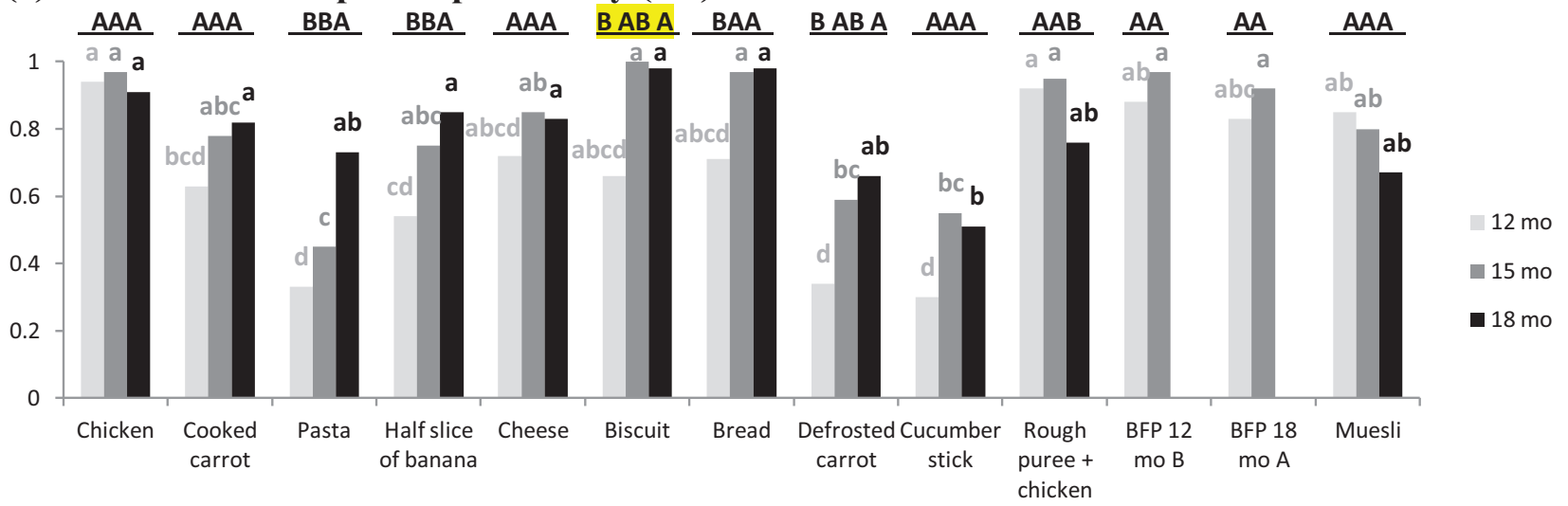

(2) Sucking probability (SP)

AAA AAA AAA AAA AAA ABB AAA AAA AAA AAA AA AA AAA

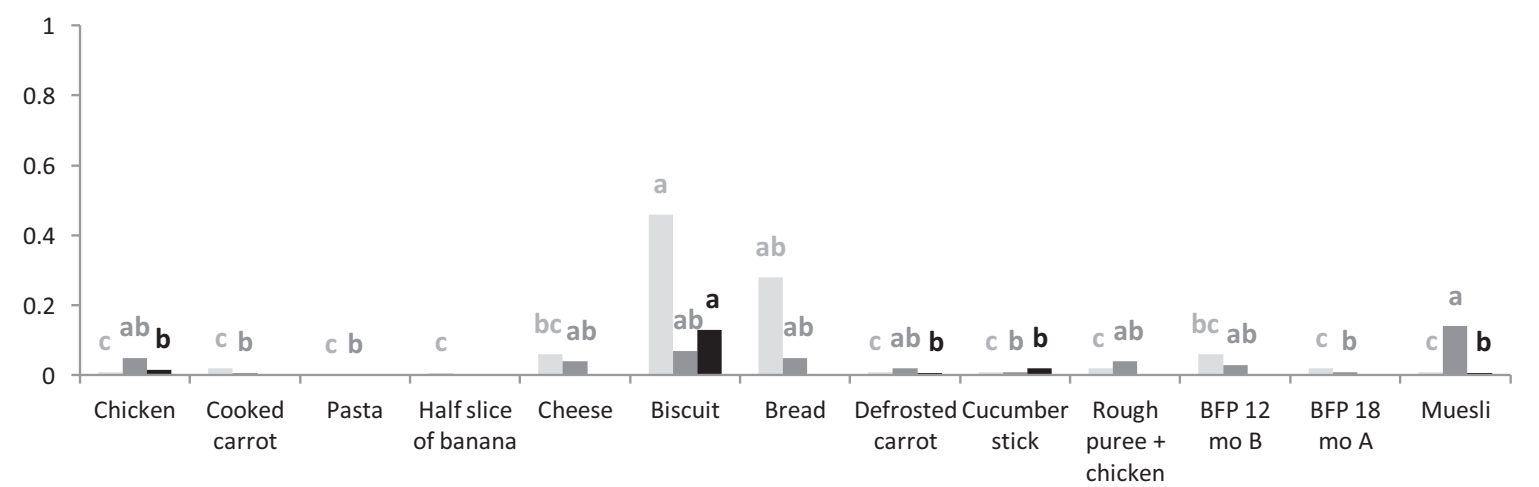

(3) Chewing probability (CP)

AAA AAA BBA BBA BABA AAA AAA BABA AAA AAB AA AA AAB

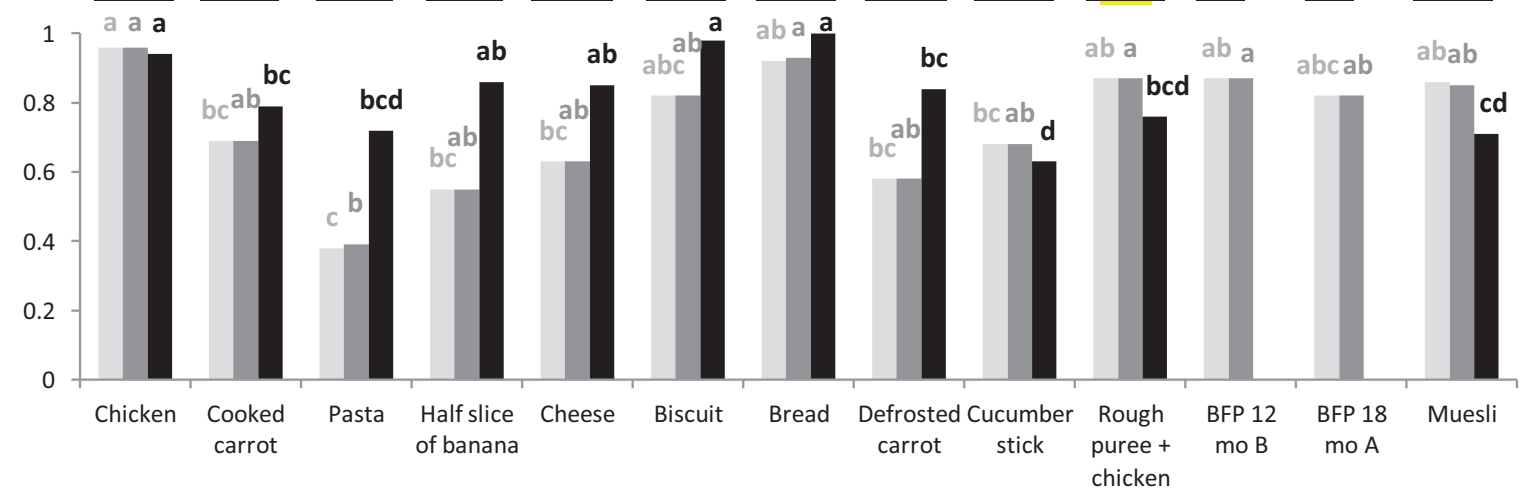

$12 \mathrm{mo}$

$15 \mathrm{mo}$

- $18 \mathrm{mo}$

$12 \mathrm{mo}$

$15 \mathrm{mo}$

$\mathbf{\square} 18 \mathrm{mo}$

\section{(4) Food texture liking}

AAA B AB A BBA CBA BAA AAA AAA BBA AAA AAB BA 


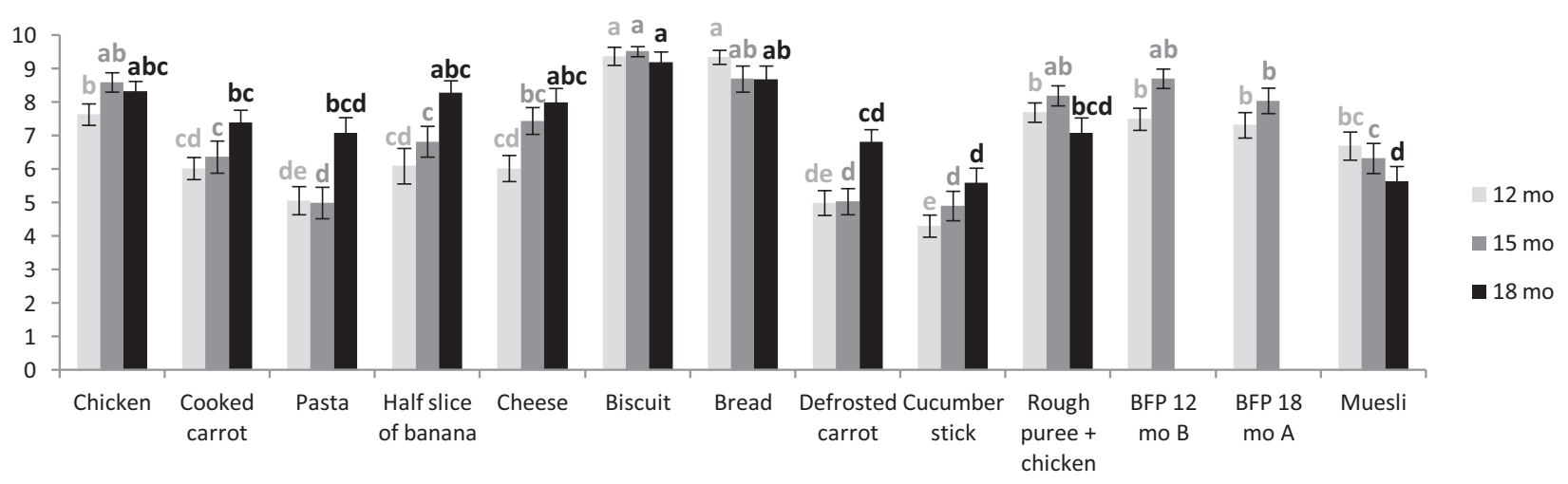

Figure 3. Estimated probabilities of acceptance (1), sucking (2), chewing (3) and mean $( \pm$ SEM) liking scores (4) of each food texture at each followed-up age in the second group of children (12, 15 and 18 months). For a given age, food-textures related differences in probabilities were assessed using Bonferroni correction: foods with the same lowercase letter are not significantly different $(\mathrm{p}<0.05)$. For a given food texture, age-related differences in probabilities were assessed by the Tukey test and were represented by letters in uppercase. For the liking, age-related differences in liking were assessed with the Student-NewmanKeuls test. Ages with the same letters are not significantly different $(p<0.05)$. The range of food textures included soft cooked pieces (cooked carrot pieces, commercial baby food pasta and shredded chicken), hard foods (defrosted carrot pieces and raw cucumber stick, commercial baby biscuit and bread), double textures (rough puree $\&$ chicken, experimental baby foods recipes BFP $12 \mathrm{mo}$ B and BFP $18 \mathrm{mo}$, and commercial baby food muesli) and sticky foods (half slice of banana and cheese). 


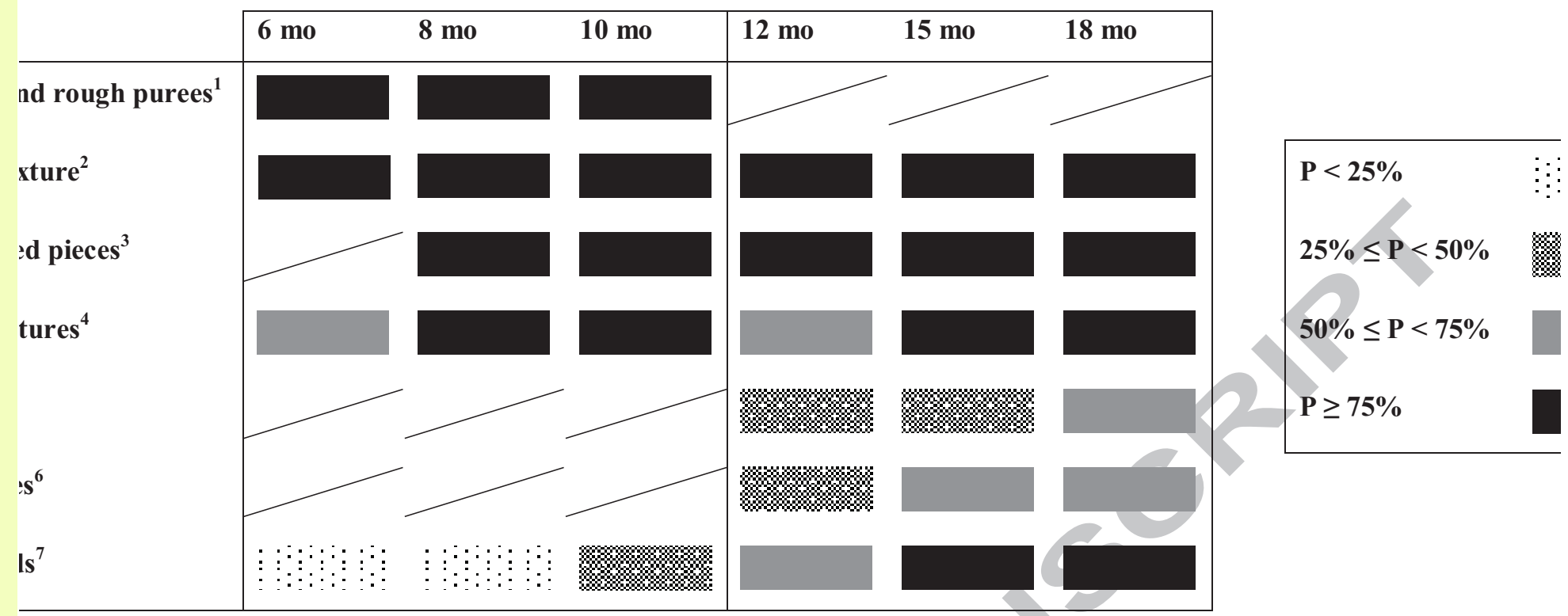

Figure 4. Summary of the observations made in the study regarding the acceptance of food with different textures between 6 and 18 months. P: probability of acceptance ${ }^{1}$ smooth and rough carrot puree, ${ }^{2}$ experimental baby foods and muesli, ${ }^{3}$ cooked carrot pieces and shredded chicken, ${ }^{4}$ mashed banana, half-slice of banana, cheese, ${ }^{5}$ penette pasta, ${ }^{6}$ defrosted carrot pieces and raw cucumber pieces, ${ }^{7}$ baby biscuit, crusty bread ends. This table reflects the observation for most foods, deviations from the table are as follows: acceptance of muesli at $18 \mathrm{mo}$ (double texture, $\mathrm{AP}=67 \%$ ); cooked carrot pieces at $12 \mathrm{mo}$ (soft cooked pieces, $\mathrm{AP}=63 \%$ ); mashed banana at 6 mo (sticky texture, $\mathrm{AP}=78 \%$ ); bread at 10 mo (hard food, $\mathrm{AP}=54 \%$ ). 
Table 1: List of the foods with different textures offered at a given age

\begin{tabular}{|c|c|c|c|c|c|c|c|c|c|c|c|c|c|}
\hline \multirow[t]{3}{*}{ Food Textures } & \multicolumn{6}{|c|}{$\begin{array}{l}\text { Age of offering } \\
\text { in the study } \\
\text { (in month) }\end{array}$} & \multicolumn{6}{|c|}{$\begin{array}{l}\text { Proportion of the } \\
\text { children that had been } \\
\text { offered the food at a } \\
\text { given age (in } \%)^{a}\end{array}$} & \multirow[t]{3}{*}{ Quantity offered ${ }^{b}$} \\
\hline & \multicolumn{3}{|c|}{ G1 } & \multicolumn{3}{|c|}{ G2 } & \multicolumn{3}{|c|}{ G1 } & \multicolumn{3}{|c|}{ G2 } & \\
\hline & 6 & 8 & 10 & 12 & 15 & 18 & 6 & 8 & 10 & 12 & 15 & 18 & \\
\hline \multicolumn{14}{|l|}{ Simple textures: } \\
\hline Smooth carrot puree ${ }^{b}$ & $\checkmark$ & $\checkmark$ & & & & & 92 & 100 & 96 & 96 & 100 & 92 & 3 spoons \\
\hline Rough carrot puree ${ }^{\mathrm{b}}$ & $\checkmark$ & $\checkmark$ & $\checkmark$ & & & & 32 & 54 & 88 & 89 & 96 & 92 & 3 spoons \\
\hline \multicolumn{14}{|l|}{ Soft and cooked pieces: } \\
\hline $\begin{array}{l}\text { Cooked carrot pieces } \\
\left(6^{*} 6^{*} 20 \mathrm{~mm}\right)^{\mathrm{b}}\end{array}$ & & $\checkmark$ & $\checkmark$ & $\checkmark$ & $\checkmark$ & $\checkmark$ & 0 & 17 & 46 & 30 & 77 & 96 & 3 pieces \\
\hline basta penette, Danone brand & & & & $\checkmark$ & $\checkmark$ & $\checkmark$ & 0 & 0 & 4 & 7 & 46 & 76 & 3 pieces \\
\hline $\begin{array}{l}\text { Shredded chicken }(8 * 3 * 3 \\
m m)^{\mathrm{b}}\end{array}$ & & & & $\checkmark$ & $\checkmark$ & $\checkmark$ & 4 & 8 & 21 & 37 & 81 & 100 & 3 spoons \\
\hline
\end{tabular}

\section{Hard textures:}

Defrosted carrot pieces $(6 * 6 * 20 m m)^{\mathrm{c}}$

Cucumber pieces $\left(6 * 6^{*} 20 \mathrm{~mm}\right)^{\mathrm{c}}$

Baby biscuit, Danone brand

Crusty bread ends: French baguette $(5 \mathrm{~cm} \text { length })^{\mathrm{C}}$

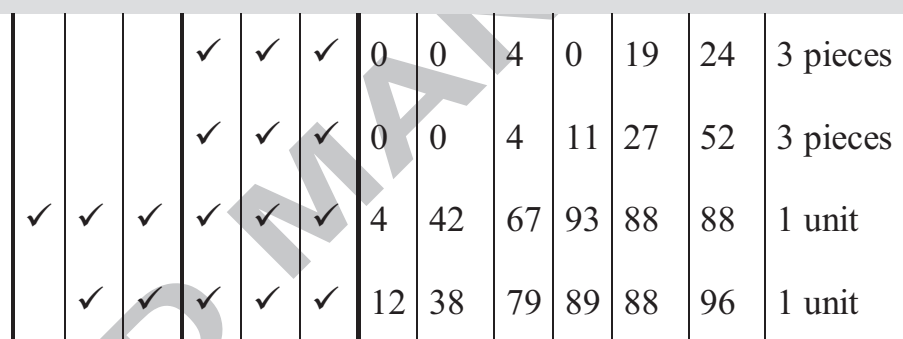

\section{Double textures:}

$\mathrm{BFR}^{*} 8$ mo: carrot, rice, beef $^{\text {b }}$

(69.9\% of puree; $15.5 \%$ of pieces $<2 \mathrm{~mm} ; 1.3 \%$ of pieces $>4 \mathrm{~mm}$ )

$\mathrm{BFR}^{*} 12$ mo A; carrot, mixed beef, potatoes ${ }^{b}$

(82.7\% of puree; $0.5 \%$ of pieces $<2 \mathrm{~mm} ; 15.3 \%$ of pieces $>4 \mathrm{~mm}$ )

BFR* 12 mo B: carrot, granular beef, potatoes ${ }^{\mathrm{b}}$

(83.6\% of puree; $0.4 \%$ of

pieces $<2 \mathrm{~mm} ; 10.9 \%$ of

pieces $>4 \mathrm{~mm}$ )

$\mathrm{BFR}^{*} 18$ mo: carrot, pasta, beef $^{\text {b }}$

(47.5\% of puree; $0.5 \%$ of pieces $<2 \mathrm{~mm} ; 46.5 \%$ of pieces $>4 \mathrm{~mm}$ )

Rough carrot puree and macaroni ${ }^{\mathrm{b}}$

(86.7\% of puree; $6.0 \%$ of pieces $<2 \mathrm{~mm} ; 4.3 \%$ of

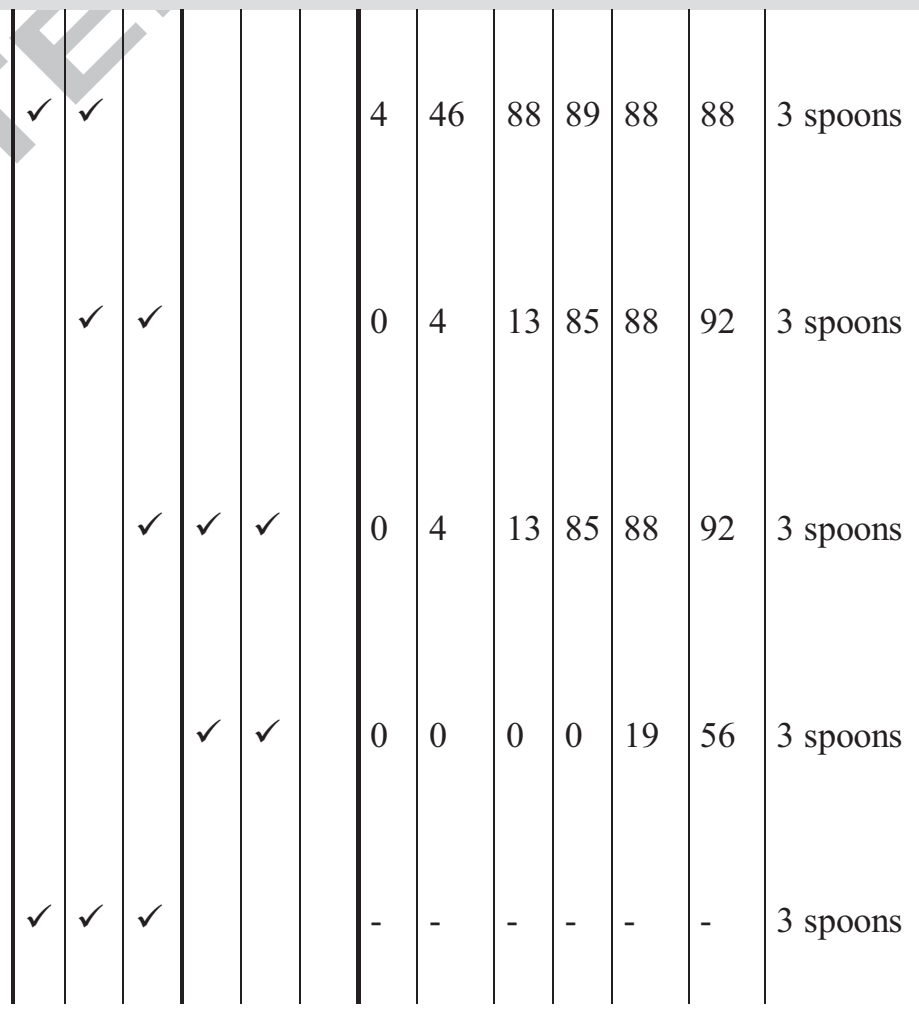




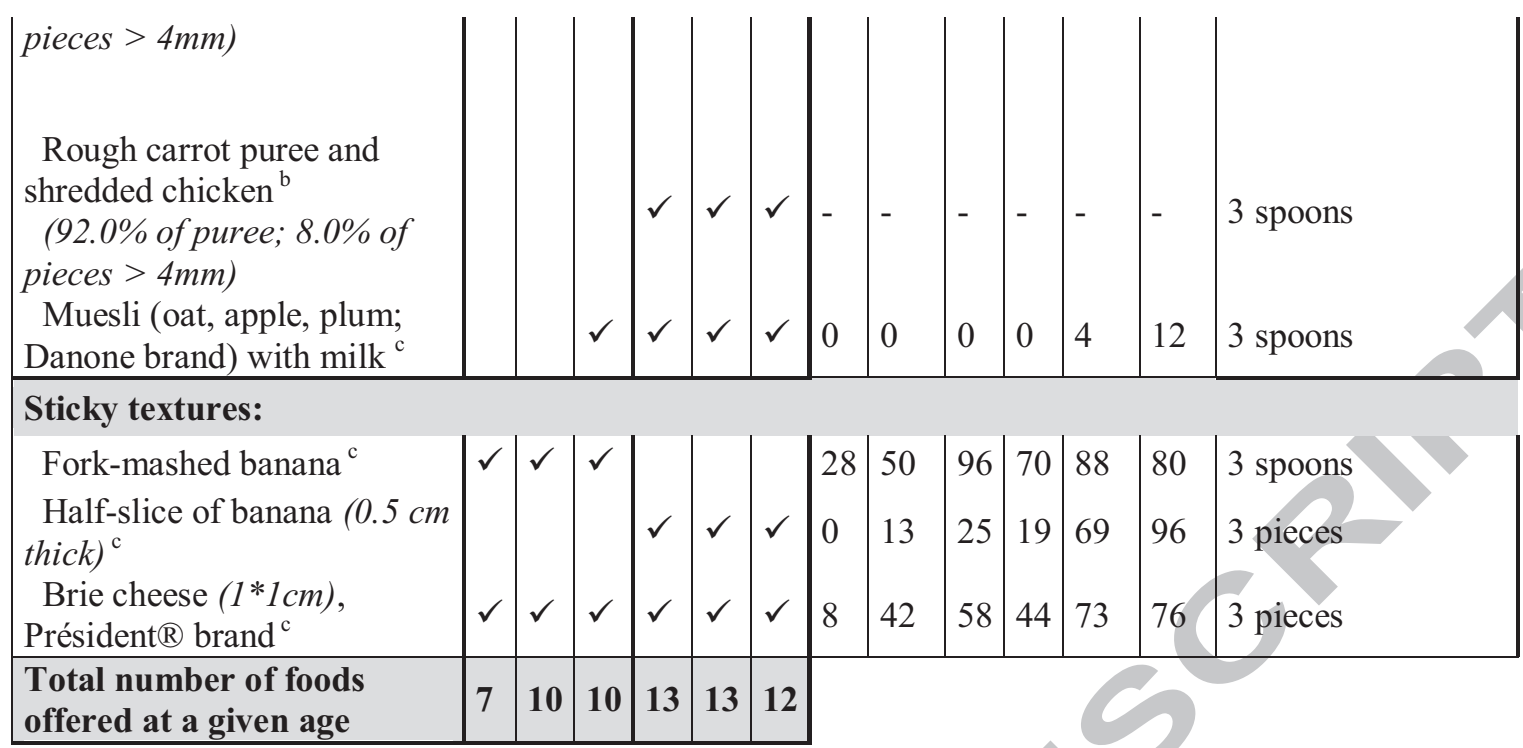

*BFR: Baby Food Recipe;

${ }^{a}$ : at each age, parents reported whether they already offered the food to their child in a self-reported questionnaire.

b: served warm $\left(44^{\circ} \mathrm{C} \pm 2{ }^{\circ} \mathrm{C}\right)$

c: served at room temperature 
Table 2: Children's and mothers' characteristics

\begin{tabular}{|c|c|c|c|c|c|c|}
\hline \multirow[b]{4}{*}{$\begin{array}{l}\text { Target age for children's } \\
\text { observation }\end{array}$} & \multirow{2}{*}{\multicolumn{6}{|c|}{ Age groups }} \\
\hline & & & & & & \\
\hline & \multicolumn{3}{|c|}{ Group 1 (6-10 mo) } & \multicolumn{3}{|c|}{ Group 2 (12-18 mo) } \\
\hline & $6(n=25)$ & $8(n=24)$ & $\begin{array}{l}10 \\
(n=24)\end{array}$ & $\begin{array}{l}12 \\
(n=27)\end{array}$ & $15(n=25)$ & $18(n=25)$ \\
\hline \multicolumn{7}{|l|}{ Children's characteristics } \\
\hline Age (months) at the first session & $\begin{array}{l}6.11 \pm \\
0.12 \\
\end{array}$ & $\begin{array}{l}8.07 \pm \\
0.13 \\
\end{array}$ & $\begin{array}{l}10.08 \pm \\
0.19\end{array}$ & $\begin{array}{l}12.1 \pm \\
0.16\end{array}$ & $\begin{array}{l}15.07 \pm \\
0.16\end{array}$ & $\begin{array}{l}18.04 \pm \\
0.16\end{array}$ \\
\hline \multicolumn{7}{|l|}{$\operatorname{Sex}(n)$} \\
\hline Girl & 11 & 11 & 11 & 11 & 11 & 11 \\
\hline Boy & 14 & 13 & 13 & 16 & 14 & 14 \\
\hline \multicolumn{7}{|l|}{ Birth order (n) } \\
\hline 1st born & 13 & 13 & 13 & 12 & 12 & 12 \\
\hline 2nd born and more & 12 & 11 & 11 & $15 \cup$ & 13 & 13 \\
\hline Number of teeth & $\begin{array}{l}0.48 \pm \\
0.77\end{array}$ & $\begin{array}{l}1.25 \pm \\
1.42\end{array}$ & $\begin{array}{l}2.91 \pm \\
1.89\end{array}$ & $\begin{array}{l}5.37 \pm \\
2.91 \\
\end{array}$ & $\begin{array}{l}8.88 \pm \\
3.75\end{array}$ & $\begin{array}{l}11.58 \pm \\
4.28 \\
\end{array}$ \\
\hline $\begin{array}{l}\text { Age at the start of complementary } \\
\text { feeding (months) }\end{array}$ & $4.71 \pm 0.3$ & & & $4.61 \pm$ & & \\
\hline \multicolumn{7}{|l|}{ Type of milk feeding (n) } \\
\hline Breastfeeding & 21 & 20 & 20 & 16 & 16 & 16 \\
\hline Bottlefeeding & 4 & 4 & 4 & 11 & 9 & 9 \\
\hline $\begin{array}{l}\text { Still breast-fed at the time of the } \\
\text { session (n) }\end{array}$ & 9 & 7 & 6 & 0 & 0 & 0 \\
\hline \multicolumn{7}{|l|}{ Mother's characteristics } \\
\hline $\begin{array}{l}\text { Age (years) at the first session for } \\
\text { each age }\end{array}$ & $32.30 \pm 3$ & & & $31.33 \pm$ & & \\
\hline
\end{tabular}

Values are the means \pm sd or $n$. 
Highlights

- Food texture acceptance was studied longitudinally between 6 and 18 mo

- Foods were offered before most of the children received them at home

- Sticky textures were accepted from $8 \mathrm{mo}$; hard foods from $12 \mathrm{mo}$; raw pieces from $18 \mathrm{mo}$

- Chewing emerged at 8 mo and was well established at 10 mo

- The acceptance of hard textures coincided with the emergence of chewing behaviour 